\title{
Entrevista
}

\section{Armando Malheiro da Silva}

Historiador, Filósofo, Arquivista e Bibliotecário, o professor livre-docente Armando Manuel Barreiros Malheiro da Silva tem se dedicado à Ciência da Informação, em suas interfaces interdisciplinares, desde a década de 1990. Hoje, professor catedrático ou titular da Faculdade de Letras da Universidade do Porto e Investigador do Centro de Investigação em Comunicação, Informação e Cultura Digital - CIC Digital-Porto, bem como Colaborador do Centro de Estudos Interdisciplinares do Século XX da Universidade de Coimbra (CEIS 20). Dentre os seus estudos, destacam-se pesquisas e a larga experiência na aplicação de metodologia para a avaliação do fluxo informacional a partir de uma perspectiva que conecta disciplinas desde a Arquivística até as Ciências Sociais.

Em diálogo científico constante com pesquisadores brasileiros, adotou e deu aplicações ao "Método Quadripolar", que tem despertado interesse cada vez maior por parte dos leitores dos artigos e livros que publica. Na ocasião, desta entrevista, explana sobre as operações da metodologia de trabalho científico, envolvendo o fluxo informacional, e aborda o binômio documento-informação, lançando luz às questões do mercado profissional para Bibliotecários, Documentalistas e Arquivistas no Brasil. A entrevista foi concedida durante reunião de orientação, realizada em 4 de março de 2015, nas dependências da Faculdade de Letras da Universidade do Porto, ao longo do desenvolvimento do pós-doutoramento da Prof. ${ }^{\text {a }}$ Dra. Sílvia Maria do Espírito Santo (Faculdade de Filosofia, Ciências e Letras da Universidade de São Paulo - FFCLRP/USP). A entrevista foi revista pelo professor em fevereiro de 2019. 
InCID: A abordagem da informação conhecida como Método Quadripolar, divulgada pelo Senhor e pela Prof. ${ }^{a}$ Fernanda Ribeiro na Universidade do Porto, possui algumas premissas essenciais. Antes de compreendermos o método, poderia contextualizar alguns conceitos subjacentes a ele?

Malheiro da Silva: A premissa inicial distingue documento de informação, e isso é muito importante. Quando falo de "Sistema de Informação" não me refiro a nenhum método e sim a uma teoria, a um modelo. O sistema é um modelo. Quando olho para a informação como sistema, prefiro chamar de "Sistema de Informação" do que de "coleção", por exemplo, ou de tratá-la como objeto de Arquivo, da Biblioteca e do Museu. Para mim, não há separação possível entre o que seria um documento "puro" e isento de qualquer dado de ordem social. A informação, concebida como um sistema, conforma um fenômeno social.

Geralmente, na Arquivística, por causa da influência da Arquivologia espanhola no Brasil, o arquivista brasileiro é uma espécie de "manga de alpaca", de notário ou escrivão judicial, porque vê o documento de arquivo fundamentalmente como uma prova, como algo isento de significados. O documento é prova, exemplo: para se adquirir uma propriedade fazse no cartório uma escritura e nela são postos selos e carimbos etc. Quanto mais carimbos eu puser no papel, mais isto fica com valor de prova. Não percebem, porém, que alguém está construindo a prova; logo, se trata de um significado construído e duplo porque é prova para quem a faz e, paradoxalmente, é um outro tipo de prova para quem precisa dela. Isso é muito complicado.

Na Biblioteconomia, por sua vez, o documento converte-se depois em informação, mas chega às mãos do bibliotecário e do documentalista como documento, como artefato material, pois o foco está no acesso ao conteúdo do documento e não tanto nas questões relacionadas com a sua produção. Apareceu aí no processo catalográfico a noção meio mística ou difusa de "obra", algo que um gênio cria e que vai parar nas mãos de um privilegiado intelectual. Cabe ao documentalista, nomeadamente através da indexação, desligar a informação do documento; operação que o arquivista também faz, mas que se recusa admitir ou reconhecer porque está amarrado à noção de prova documental e, nesta noção de prova, o suporte material confere autenticidade e fiabilidade ao conteúdo. É nesse momento de epifania que o documentalista ou o bibliotecário "descobre" a informação. Isso é bonito porque percebe que há informação. Mas a informação chega às suas mãos a partir do contexto 
de produção, quer dizer, o contexto de produção é desconhecido para o documentalista no início dos seus procedimentos.

A título de ilustração, observe que uma pessoa como você produz enquanto autora um texto e irá entregá-lo a um mediador, que é o editor. O livro sai do prelo e vai parar em uma biblioteca pública ou especializada, um Centro de Documentação onde um documentalista começa a catalogar a obra. Mas, para ele, como o livro foi produzido e o porquê aparece um prefácio de, por exemplo, um tal Armando Malheiro são mistérios que não lhe interessa resolver. Há um genérico e assumido desprezo pelo contexto de produção. Este contexto, ao contrário, pode e deve interessar ao arquivista tanto quanto tem de interessar o contexto de produção de qualquer peça ou artefato da "coleção museológica". Para o arquivista a prova nasce com o autor, porém, em termos descritivos inventou-se nos termos da Norma Geral Internacional de Descrição Arquivística (ISAD-G) o campo de autoridade, ou seja, a prova nasce em instância de poder e é criado o campo "autoridade" para se mencionar o autor. Não é curioso? É até complicado, pois não deveria haver autoridade, deveria haver apenas autor. Converter o autor em autoridade tem muito que se diga.

InCID: O senhor está afirmando que essa diferença conceitual, até mesmo a dificuldade em diferenciar o que é um documento do que constitui uma informação - ou seja, certa leviandade em atribuir valor de verdade a qualquer documento devido ao seu status, sem compreender que nele estão forjadas informações de ordens variadas - encontram lastro na formação superior destes profissionais? Isso nos dá pistas sobre como a sociedade como um todo percebe e lida com a informação?

Malheiro da Silva: Certamente sofre influência dos modelos de ensino superior que envolvem a Ciência da Informação. O que é interessante é que um documentalista que desconhece o contexto de produção, que expõe o documento como um objeto, um artefato, está a operar uma "rotura informacional", está a apagar a informação que explica em larga medida o conteúdo (informação) daquele documento. Por outro lado, esse documentalista está se convertendo em cibernauta - quando passa o conteúdo de um documento para um banco de dados está fazendo uma transmutação de suporte, o que é desafiante, porque o obriga a controlar e saber novas linguagens, e dominar um novo fetiche, que é a tecnologia informática -, no entanto, para isso precisa ter competências dadas pela Formação superior que recebe e que o habilitem a assumir esse desiderato, mas o que sucede, na prática, é a apenas manifestação do seu desejo de atingir o estatuto de um "novo profissional", tocado pelo 
prestígio simbólico dado pelo fetiche tecnológico em voga. O bibliotecário, nesse sentido, está à frente, porque começou a ter que se render à tecnologia, e o arquivista, não. $\mathrm{O}$ arquivista, no Brasil, está na idade da pedra e sim, isso vem desde a sua formação.

No Brasil ouso dizer que o problema é que há forças, e de formas enviesada, interessadas em resistir à revolução tecnológica em curso. O Brasil vai ter que ter profissionais para lidar com os problemas da informatização do século XXI, que já chegou ao Brasil. Os celulares e smartphones estão a ser usados dentro da vida multisetorial de cada um, ao mesmo tempo em que subsiste o documento em papel, e esta coexistência vai ficando cada vez mais confusa e problemática. Sabem usar aplicativos complicadíssimos e, ao mesmo tempo, têm que ir ao cartório para bater carimbos quando não devia haver mais carimbo no Brasil, nem em parte nenhuma! Aqui já acabamos com o papel selado, e isso foi uma grande revolução. O papel selado vem quase do Tempo das Caravelas e acabou oficialmente em 1998 e foi uma conquista de modernização administrativa do país. O cidadão deixou de comprar uma folha de papel selado para fazer um requerimento em folha de papel A4, datilografado, assinado, de preferência, e se possível carimbado. Que sentido faz usar um papel selado num país que estava caminhando para o século XXI? Ora, o Brasil tem o papel selado, de uma forma pior, na imposição do Cartório, com carimbos e com reconhecimento de firma, que é uma coisa humilhante, quer dizer, reconhece-se a assinatura! A pessoa tem que ser reconhecida como sendo o Eu várias vezes, por um notário. Um país assim, como muitos, um país que foi colônia, hoje emergente e confuso porque está vivendo ao mesmo tempo vários tempos. Tem que ser híbrido, a palavra é "híbrido". Provavelmente vai ter vários problemas, porque vai ter ali vários mundos a divergir dentro dele. Há aí um mercado ou mercados a demandar profissionais com um novo perfil... O bibliotecário é uma espécie em transmutação, tal como o arquivista. O bibliotecário vai se tornar cada vez mais raro no Brasil e terá de se tornar um informatólogo ou tecnólogo, senão não sobrevive. Faz biblioteconomia e tem que fazer tecnologia. Mas quem vai sobreviver no grande mercado que está aí é, obviamente, o que tem esse viés tecnológico. E vai haver discriminação salarial: os que lidam com livros impressos e documentos em papel serão remunerados de forma bem mais inferior que os gestores de informação eletrônica, dos gestores de dados etc.

Agora, a questão do Brasil é a seguinte: o que se faz nas favelas, o movimento natural de criar bibliotecas como espaços divertidos, mas também de reabilitação social, é uma exigência por demais evidente na América do Sul, em África e em continentes onde as assimetrias sociais e o atraso civilizacional ainda é acentuado. São essas assimetrias num país 
entre o progresso, o passado, a cultura e o mercado que são verdadeiramente desafiadoras hoje e têm implicações no modelo formativo dos profissionais da documentação e informação. O panorama é extraordinariamente complexo, mas o que eu vejo é que o Brasil como aqui em Portugal também - está muito mal preparado para enfrentar o futuro imediato. A tônica sutil na tecnologia que tem prevalecido nos discursos eufóricos da mídia sobre os cientistas da informação é um sinal sutil destas mudanças...

\section{InCID: No sentido das mudanças esperadas no mercado e, principalmente, no campo dos estudos sobre a Informação, quais as especificidades do curso de Ciência da Informação oferecido na Universidade do Porto?}

Malheiro da Silva: Sobre a formação do curso, o Professor Doutor José Marques, padre católico e cônego na Sé Primaz de Braga, era também professor de História Medieval e um especialista nas áreas de Diplomática e Codicologia na Faculdade de Letras da Universidade do Porto, e foi quem trouxe o curso de especialização em Ciências Documentais de Coimbra para o Porto. À época contratou dois assistentes: a Prof. ${ }^{a}$ Elisa Cerveira (Biblioteconomia) e a Prof. $^{\text {a }}$ Fernanda Ribeiro (Arquivística). Após a graduação ofertava-se em dois anos a especialização em Arquivo ou Biblioteca, e foi esta a formação dada no Porto, de 1985 a 2001. Nesse movimento buscou-se agregar estudiosos como, por exemplo, o historiador e arquivista galego Pedro Lopez Gomez, então diretor do Arquivo da Corunha, na Galiza.

A Arquivística é, literalmente, filha da História. Em concreto, a História Medieval exerceu uma influência decisiva na Arquivística, apoiando-se na técnica de descrever e classificar os documentos antigos e manuscritos/paleográficos para reconstituir/reinventar a memória, buscar um passado glorioso que constituísse a identidade nacional. Vamos ser claros: a Arquivística é uma espécie de "instrumento clínico" da História que a ajuda a operar sobre o passado... E dentro da História temos o ramo da Medieval voltado para o estudo da Igreja e das Chancelarias Régias, valorizando os aspectos institucional e administrativo. E na transição do período medieval para o moderno acentua-se o interesse pelo processo de centralização do Estado capaz de unificar diferentes nações. Cria-se, assim, um centro e, afastando o regionalismo, ele é colocado sob controle.

Há, portanto, um controle por parte do Estado e esse controle exige instrumentos de memória e instrumentos ideológicos. O Arquivo Geral de Simancas, por exemplo, foi construído para ser o arquivo do Estado espanhol, e é uma fortaleza. É necessário o exercício de uma leitura sociológica e política das instituições para compreendê-lo enquanto um 
Sistema de Informações, e é muito interessante. Nesta Faculdade há um mestrado de História e Patrimônio onde há interpretações sobre arquivos, e a minha colega Fernanda Ribeiro e eu fomos envolvidos a lecionar uma disciplina (no caso dela) e a orientação de dissertações (ela e eu). Os colegas da História consideram o patrimônio como conceito que interessa à História, ao Museu, um conceito fácil de manipular pela História, porque cabe ali uma herança cultural e, portanto, dá para meter muita coisa: o que interessa e o que não interessa. Para nós, se trata de um conceito que permite uma certa manipulação; dentro do patrimônio, há coisas muito diferentes.

\section{InCID: Neste contexto onde deve-se valorizar a informação em termos conceituais, do que se trata o que ficou conhecido como Método Quadripolar? Qual a sua origem no âmbito das Ciências Sociais e do tratamento dado ao documento?}

Malheiro da Silva: As Ciências Sociais enfrentavam um problema epistemológico de objetividade que foi se agravando nos anos 1960 e 1970 com o estruturalismo, quando começou a se acentuar o debate entre o que é verdadeiramente ciência e o que não é. E aquilo que era ciência estava a se traduzir em tecnologia, que são as ciências duras, experimentais e naturais: que vão para o laboratório e fazem a bomba atômica etc. Essa era a Ciência. As Ciências Sociais querem afirmar sua cientificidade, mas têm alguns problemas sérios do ponto de vista epistemológico. Um deles é que aquilo que elas estudam envolve e implica o próprio investigador: o sujeito que estuda. Estamos a tocar no complexo problema da subjetividade do cientista social.

O positivismo, visto e analisado, acabava pondo em xeque as possibilidades científicas da própria ciência social, porque quando, por exemplo, a História pretendeu ser uma ciência, tornou-se demasiado positivista e acreditou, por exemplo, no documento. A verdade estava no documento. A História Nova, nos anos vinte do século passado, veio mostrar que o documento é uma interpretação mais que propriamente uma verdade inscrita. A verdade não estava no documento; estava, muito possivelmente, na interpretação de quem encontra e lê o documento. E essa verdade cabia em cada um. A excessiva deriva positivista estourou com a credibilização científica da História. Ora, isto trouxe para as Ciências Sociais o problema crítico de sua cientificidade, que passava, também, por se ter um método. Podem as Ciências Sociais usar o método das Ciências Naturais? Achou-se que sim e essa mania ainda persiste.

Então, eu me lanço a fazer inquéritos e vou buscar, no respetivo tratamento estatístico, uma pseudocientificidade. Só que a estatística vale aquilo que eu fizer com ela. E, então, 
surgem problemas porque eu posso formalmente copiar o método das Ciências Naturais, mas há problemas concretos que emergem da dimensão humana e social, problemas que resistem a serem operados através de um método estritamente natural, ou experimental. Então, o Jean Ladrière (filósofo das ciências e matemático belga), prefaciador da obra "Dinâmica da Pesquisa em Ciências Sociais" (1974), colocou esse problema.

Se calhar, as Ciências Sociais podem conquistar cientificidade sem ficarem presas a um método que não é próprio delas. Têm que criar o seu próprio método, ou seja, têm que ajustar a metodologia aos seus problemas. Têm que usar o binômio quantitativo e qualitativo e que todos hoje usam, porque quantificar é entendido como sinónimo de exatidão, de rigor, numa palavra, de cientificidade tão necessária às Ciências Sociais. E o qualitativo é o quê? Embora não goste da palavra, direi que é o saber interpretar dados mensuráveis que são muito comuns nas Ciências Naturais. Por isso é que também se chama o método quadripolar de investigação qualitativa.

Assim, esta metodologia constitui uma organização do método científico que, ao invés de ser linear, introduz polos ou componentes em espiral ou vórtex, e não de modo linear, a fim de haver outra liberdade de operacionalização metodológica. Propõe-se, então, que muitas dessas "operações" sejam feitas lendo as informações não em um plano puramente cartesiano de problema-hipótese-leitura de exploração-análise-resultados, mas sim da perspectiva de polos que se inter-relacionam a todo o momento com liberdade de movimentação.

InCID: Este método científico propõe quatro polos para a leitura da informação: os polos epistemológico, teórico, técnico e morfológico. $O$ primeiro deles é considerado o mais essencial desde o início de uma ação de investigação científica, por quê?

Malheiro da Silva: O primeiro é o polo epistemológico, ou seja, a primeira coisa que o investigador social tem que fazer é pôr-se em si, pôr-se em autovigilância crítica porque o investigador em Ciências Sociais é um sujeito/ator que vai condicionar a pesquisa, sempre. Não há objetividade pura. Há subjetividade sim, ela é um dado epistemológico, mas temos que fazer o autoexame no sentido de ir criando filtros para permitir que essa subjetividade não fique atuando perversamente no trabalho.

Portanto, o primeiro grande polo exige do sujeito-investigador em Ciências Sociais que se coloque sempre em causa. É o exercício crítico que eu acho uma "trave-mestre". O sujeito, se não entrar em paranoias ideológicas ou relativistas, sabe que desta postura depende 
muito do bom resultado do seu trabalho. Mesmo sabendo que há opções ideológicas que são difíceis de controlar, é possível adotar filtros de controle bastante satisfatórios. Ainda assim, o sujeito de investigação em Ciência Social escolhe os temas de acordo com sua pertinência, e não de forma imposta de fora.

O famoso Michael Polanyi, o homem que criou a expressão "conhecimento tácito", formulou, nos anos 1940, a teoria de que a investigação científica não se baseava apenas no trabalho lógico-dedutivo, em sentido puro, porque o lado emocional, cognitivo e psíquico de cada investigador interferia no processo de pesquisa e de descoberta. Na própria Ciência Natural, por exemplo, Albert Einstein projetou-se psicologicamente em suas teorias. Está lá o Einstein homem. Este é o polo epistemológico e se articula com os outros três [operacionais como base porque acompanha o sujeito na investigação toda em autoanálise. ]

O sujeito parte para a investigação assumindo as suas preferências e tentando controlálas, porém assumindo-as. O importante aqui é que tem que assumi-las. Ter consciência delas. Não se é neutro; todos temos e fazemos opções pessoais e subjetivas, e o importante é sabelas balancear através de um exigente exercício crítico. Eu posso travestir a objetividade. A objetividade só é conseguida se eu utilizar, por exemplo, mais do que uma fonte, mais do que uma técnica metodológica, por exemplo. Porque eu tenho aqui um problema: é a partir do momento em que tenho algumas teorias, algumas hipóteses que estão contaminadas ideologicamente, que eu preciso da abertura de espírito necessária para conseguir provar o contrário daquilo que eu julgava evidente e certo. Isso é possível fazer e posso dar-lhe imensos exemplos. Agora, aquele que não logra controlar o excesso de subjetividade que não investigue, que desista dessa função. Se não consegue operar através do polo epistemológico, os resultados a obter serão afetados negativamente em sua credibilidade científica.

\section{InCID: No tocante aos demais polos constituintes do método quadripolar, ou investigação qualitativa, como o investigador deve operacionaliza-los?}

Malheiro da Silva: Tudo deve ser feito de forma articulada. Os próximos polos misturam algumas etapas dessa linha tradicional, que era mesmo linear. No polo teórico formula-se a hipótese, as teorias, mas isso não é feito de forma simples ou retilínea. Eu levanto um problema e esse problema não fica definido de vez. E o polo técnico, onde estão aquelas operações mais empíricas - relativas ao trabalho de campo - é convocado em permanência e não apenas quando chegar a vez certa e única de usar essas técnicas operativas ou instrumentais. O investigador em Ciência Social não vai para laboratório. O laboratório 
começa quando está fazendo leituras e revisão de literatura, por exemplo. O nosso laboratório é um "laboratório misto", pois começamos na teoria, vamos à prática, voltamos à teoria e voltamos à prática. Misturamos teoria e prática e isso é muito diferente do investigador de Ciências Naturais, que formula uma hipótese pura para, depois, fazer a experimentação pura para provar a hipótese ou informar a hipótese. Isto é articulação. Nós trabalhamos em espiral. Estamos progredindo dando voltas, e não em linha reta.

\section{InCID: Essa articulação mantém sempre em vista um quarto polo, denominado morfológico. Como o senhor o sintetizaria e como finalizaria essa nossa breve conversa?}

Malheiro da Silva: O polo morfológico, tal como o entendo e adaptei, é a saída de resultados. À medida que vou produzindo resultados, estes confirmam ou não minha pesquisa e vão alimentando essa "máquina", esse vórtice. De modo que o método quadripolar é uma forma de figurar, em pesquisa, em espiral permanente, o que permite a cientificidade possível em Ciência Social.

Qualquer pesquisa deve, pois, ser feita com rigor acadêmico recorrendo-se a tal metodologia sem perder de vista as opções próprias da percepção e ambição de cada autor. Todo investigador de Ciência Social faz isso, mas uma coisa é fazê-lo por intuição, outra coisa é fazer com um método que diz expressamente que esse é um ponto crucial no próprio exercício metodológico: "Por baixo destas etapas todas o sujeito tem que estar em autoanálise permanente”. O sujeito parte para a investigação, assumindo suas preferências e tentando controlá-las. Isto não é dito em nenhuma metodologia formal, a não ser no método quadripolar através de suas premissas e de seus polos. Finalizada

Entrevista enviada em mar. 2019

\footnotetext{
i A entrevista original possui mais de 2 horas transcritas. Todavia, para respeitar as normas da revista InCid, suprimimos trechos do conteúdo apesar dos assuntos igualmente pertinentes. Aqui, o foco abordado, é a respeito do método Quadripolar, Arquivística e Ciência da Informação. Indicam-se algumas das discussões presentes nas esferas acadêmicas na Universidade do Porto e em outros centros científicos, no Brasil e no exterior. Sobre o método, e atendendo ao interesse dos leitores e dos pesquisadores da área, sugere-se a leitura da Revista Prisma, n. 26, (2014), disponível no site: <http://ojs.letras.up.pt/index.php/prismacom/article/view/1861>, especial sobre o Método Quadripolar.
} 